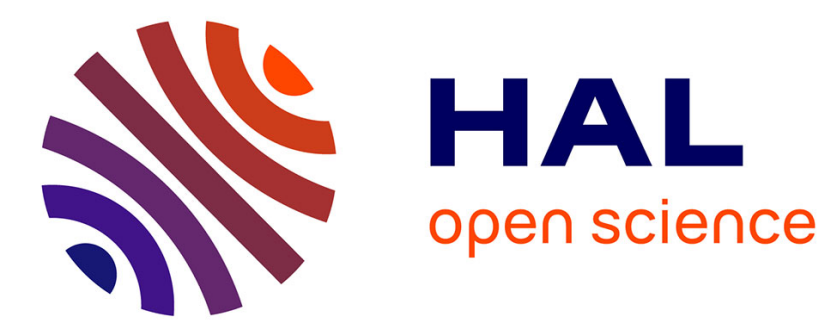

\title{
Influence of the epilayer properties on breakdown voltage and noise behaviour of GaAs MESFETs \\ C. Tsironis
}

\section{To cite this version:}

C. Tsironis. Influence of the epilayer properties on breakdown voltage and noise behaviour of GaAs MESFETs. Revue de Physique Appliquée, 1978, 13 (12), pp.761-765. 10.1051/rphysap:019780013012076100 . jpa-00244542

HAL Id: jpa-00244542

https://hal.science/jpa-00244542

Submitted on 1 Jan 1978

HAL is a multi-disciplinary open access archive for the deposit and dissemination of scientific research documents, whether they are published or not. The documents may come from teaching and research institutions in France or abroad, or from public or private research centers.
L'archive ouverte pluridisciplinaire HAL, est destinée au dépôt et à la diffusion de documents scientifiques de niveau recherche, publiés ou non, émanant des établissements d'enseignement et de recherche français ou étrangers, des laboratoires publics ou privés. 


\title{
NOISE AND CHARACTERIZATION.
}

\section{INFLUENCE OF THE EPILAYER PROPERTIES ON BREAKDOWN VOLTAGE AND NOISE BEHAVIOUR OF GaAs MESFETS}

\author{
C. TSIRONIS
}

Institute of Semiconductor Electronics, Technical University Aachen, Templergraben 55, D-5100 Aachen, R.F.A.

\begin{abstract}
Résumé. - L'analyse des petits signaux, du bruit, du régime préclaquage des dispositifs microondes en fonction de la technologie et de la géométrie des couches épitaxiées sur lesquelles sont réalisés les dispositifs, a été effectuée à partir de structures adéquates. Une couche tampon très pure réduit la température de bruit de la couche active, supprime la tendance au claquage et améliore la transconductance du MESFET près du pincement. Par traitement de surface de la région de grille, les résistances parasites sont réduites, tandis que les tensions de pincement, le bruit et le comportement «H.F. " des MESFET voient leurs performances améliorées. Le début d'un flux de courant en excès, indiquant l'amorçage du claquage, est repoussé vers les plus hautes tensions. Le même effet peut être atteint par une simple structure en escalier où la région de contact la plus épaisse est polarisée positivement.
\end{abstract}

\begin{abstract}
The dependence of small signal, noise and prebreakdown behaviour of microwave devices on technology and geometry of the epilayers on which the devices are made has been investigated by means of suitable structures. A high purity buffer layer reduces the noise temperature of the active layer, suppresses the breakdown tendency and improves the MESFET transconductance near pinch off. Etching down the gate area of MESFETs lowers parasitic resistances and improves their pinch off, noise and microwave behaviour. The beginning of an excess current flow, indicating the beginning of breakdown, is shifted to higher voltages. The same effect can be reached by a simple stepped structure, where the thicker contact area is positive biased.
\end{abstract}

1. Introduction. - The influence of technology and geometry on dc, rf, noise and burnout behaviour of GaAs FETs has been pointed out in several publications [1-6]. The use of a high resistivity buffer layer improves the dc, rf and noise characteristics [1,2], whereas the inlaid of $\mathrm{n}^{+}$regions below the drain and source contacts reduces the leading resistances and improves the breakdown behaviour [3, 4]. Higher breakdown voltages have been realized by simple recessed structures $[5,6]$, where the gate contact region was etched down in order to achieve a thin active channel region and low field values below the drain contact. The insertion of the buffer layer also reduces the equivalent noise temperature of the epilayers [7] and suppresses avalanche noise and microplasmas in FETs and channels for $V_{\mathrm{DS}}$ up to $10 \mathrm{~V}$ [8]. Increased $\mathrm{rf}$ noise temperature in the epilayer could be due to the interaction of the carriers with the substrate in the interface region [7]. The additional current flow after saturation, indicating the beginning of burnout, is due to avalanche breakdown of the back side diode near the substrate below the drain contact and depends strongly on electrical field and current density in this region. So the influence of a gate ditch on noise power and excess current flow of unbuffered devices was investigated. Also the dependence of the rf-behaviour of MESFETs on the existence of a buffer layer and a recessed gate area was inquired. The rf noise temperature of channels (ungated MESFETs) as a function of substrate bias, was measured in order to localize excess noise generation centres.

In section 2 the parameters and geometry of the investigated devices will be presented and in section 3 experimental results accompanied by a brief discussion will be given. Section 4 is the summary.

2. Test devices and structures. - Six sorts of devices were investigated, as given in figure 1. Devices D 394$2,-3$ and -4 (channels, Fig. $1 a, b, f$ ) were tested on the origin of the excess current flow and the influence of epilayer thickness on it. Devices D 353 and D 188 A (4-Gate MESFETs, Fig. $1 b, d$ ) were compared concerning the rf-behaviour ( $f_{\max }$ and noise figure) and devices H 383 H 384 (channels and MESFETs, Fig. $1 d, e$ ) were tested with regard to the distribution of noise generation centres in the epilayer and their influence on noise figure of the MESFETs. The technological and geometrical parameters of the tested devices are given on table I, dimensions are referred to figure 1 .

\section{Experimental results and discussion. -} 3.1 INFLUENCE OF THE BUFFER LAYER. - A common technological method to improve the electrical cha- 
a.

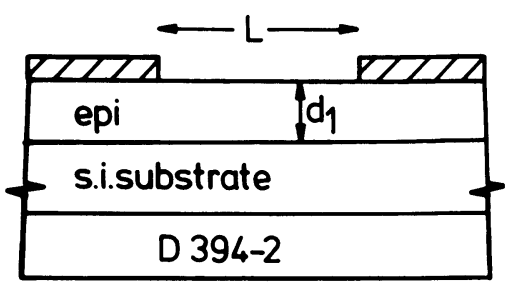

b.

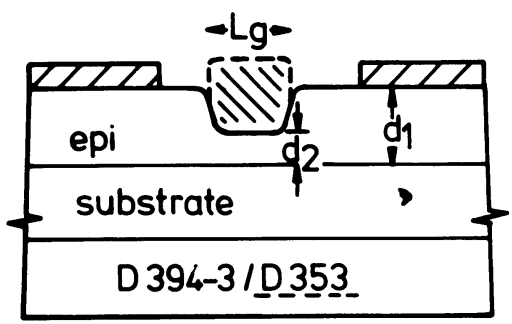

c.

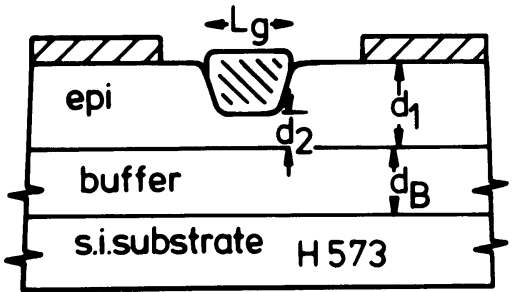

d.

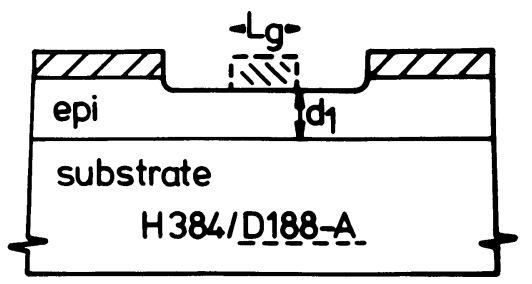

e.
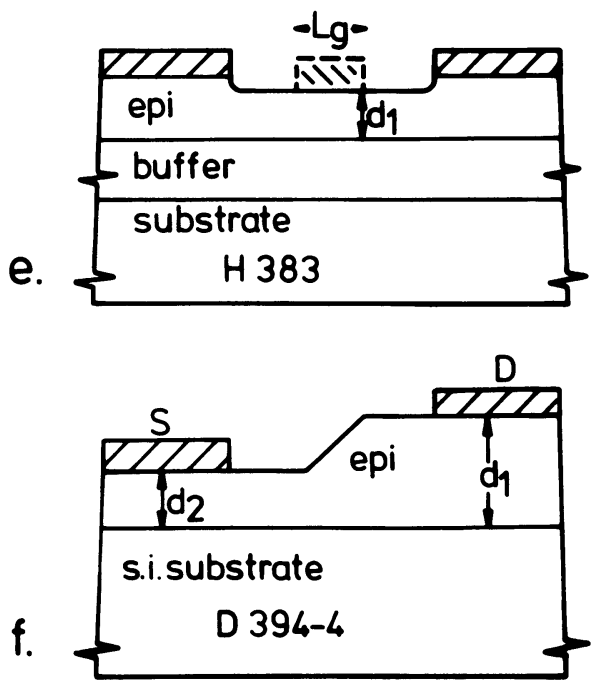

FIG. 1. - Tested devices, schematic. Gate contacts drawn by broken lines are present only on a part of the corresponding structures. Ohmic contacts : Ni-AuGe-Ni, Schottky : Cr-Ag-Cr.

TABLE I

Geometrical and technological parameters of tested structures.

THA : Inst. of Semiconductor Electronics, Technical University Aachen, BDH : BDH Chemicals Ltd

\begin{tabular}{|c|c|c|c|c|c|c|c|c|c|}
\hline Device & $N_{\mathrm{D}} / \mathrm{cm}^{-3}$ & $N_{\text {buff }} / \mathrm{cm}^{-3}$ & $L / \mu \mathrm{m}$ & $L_{\mathrm{g}} / \mu \mathrm{m}$ & $d_{1} / \mu \mathrm{m}$ & $d_{2} / \mu \mathrm{m}$ & $d_{\mathrm{Buff}} / \mu \mathrm{m}$ & $\mathrm{z} / \mu \mathrm{m}$ & $\begin{array}{c}\text { epi- } \\
\text { grown by }\end{array}$ \\
\hline 383 & $2 \times 10^{17}$ & $\lesssim 10^{14}$ & 3.2 & 1.1 & $0.1-0.15$ & - & 1.5 & 200 & THA \\
\hline H 384 & $2 \times 10^{17}$ & - & 3.2 & 1.1 & $0.1-0.15$ & - & - & 200 & THA \\
\hline H 573 & $2.5 \times 10^{17}$ & $\lesssim 10^{14}$ & 2.8 & 1.2 & $0.2-0.25$ & $0.07-0.1$ & 1.5 & 200 & THA \\
\hline D 353 & $1.5 \times 10^{17}$ & - & 3.9 & 1.35 & $0.3-0.4$ & $0.1-0.15$ & - & 800 & $\mathrm{BDH}$ \\
\hline D $394-2$ & $1.5 \times 10^{17}$ & - & 6.0 & - & 0.15 & - & - & 200 & BDH \\
\hline D $394-3$ & $1.5 \times 10^{17}$ & - & 6.0 & 1.5 & 0.25 & $0.1-0.15$ & - & 200 & $\mathrm{BDH}$ \\
\hline D $394-4$ & $1.5 \times 10^{17}$ & - & 6.0 & - & 0.25 & 0.12 & - & 200 & BDH \\
\hline D $188 \mathrm{~A}$ & $1 \times 10^{17}$ & - & 3.0 & 1.0 & 0.3 & - & - & 800 & $\mathrm{BDH}$ \\
\hline
\end{tabular}

racteristics of GaAs MESFETs is to grow a $1-10 \mu \mathrm{m}$ thick undoped layer before deposition of the active layer [1]. The interaction between the current leading path and the substrate surface, in most cases degraded by the tempering during the VPE process [9], can so be avoided. The microwave noise temperature of the active layer also depends on the quality [10] and treatment [7] of the epilayer, these properties being also affected by the substrate.

Growing by VPE a $1.5 \mu \mathrm{m}$ thick buffer layer with an undesired doping of $\lesssim 10^{14} \mathrm{~cm}^{-3}$ (Si) on one half of a Monsanto Cr-compensated Si-substrate, the equivalent noise temperature of the active layer, measured at 4.0 and $7.0 \mathrm{GHz}$ was reduced for $E=E_{\text {sat }}$ 
( $=3.2 \mathrm{kV} / \mathrm{cm}$ ) by a factor of two, compared with the unbuffered layer [7], corresponding to a lower noise figure by $0.6 \mathrm{~dB}$ at $8 \mathrm{GHz}$; the whole improvement is higher because the transconductance near pinch off is higher in buffered MESFETs than in unbuffered ones [11]. So a noise improvement by reducing the noise temperature is possible in devices with equal transconductances $g_{\mathrm{m}}$. To get more information about the noise generation density in the active layer, we measured $T_{\mathrm{n}}\left(V_{\mathrm{ss}}\right)$ of the epitaxial channels $\mathrm{H} 383$ and $\mathrm{H} 384$ at microwave frequencies.

As can be seen in figure 2, the devices without buffer layer show an increased concentration of noise sources near the substrate, whereas the curve for buffered devices indicates rather depletion near the interface to the buffer layer. Nevertheless most of the degradation in noise seems to be caused by the whole volume of the active layer. It has been pointed out $[3,8]$, that MESFET burnout is a substrate effect, initiated in the drain contact region, for planar or nearly planar devices (Fig. 1 $a, d$ ). The space charge layer of the back side diode, caused by electrons trapped in the interface region [12], plays an essential role, because here breakdown begins. A narrow high current density path is built by back side gating near the drain edge (Fig. 3), since here the electrical field, especially in ungated MESFETs, can reach very high values [13]. Figure 3 also demonstrates the effect of prebreakdown phenomena on noise figure of MESFETs. The buffer layer reduces the number of traps at the interface, so the voltage drop on the back side s.c.l. needed to pinch off the channel near the drain shifts to higher values. This effect is common in FETs with and without gates, though the existence of a negative biased gate reduces the current density

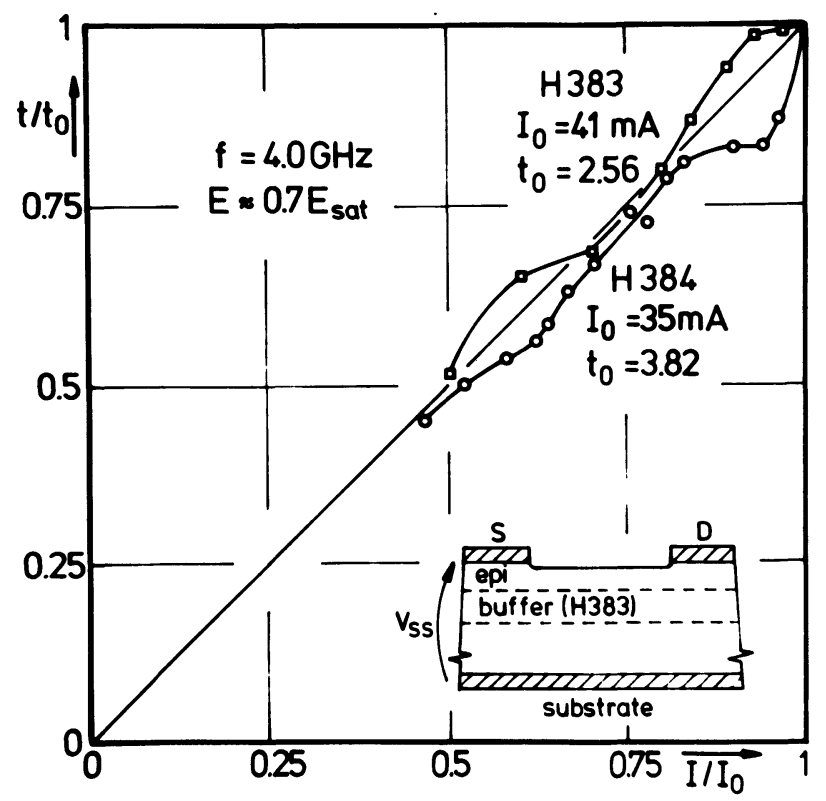

FIG. 2. - Equivalent noise temperature of epitaxial channels; $t=T_{\mathrm{n}} / T_{0}, t_{0}=T_{\mathrm{n}} /\left(V_{\mathrm{ss}}=0\right) / T_{0}, I_{0}=I\left(V_{\mathrm{ss}}=0\right)$.

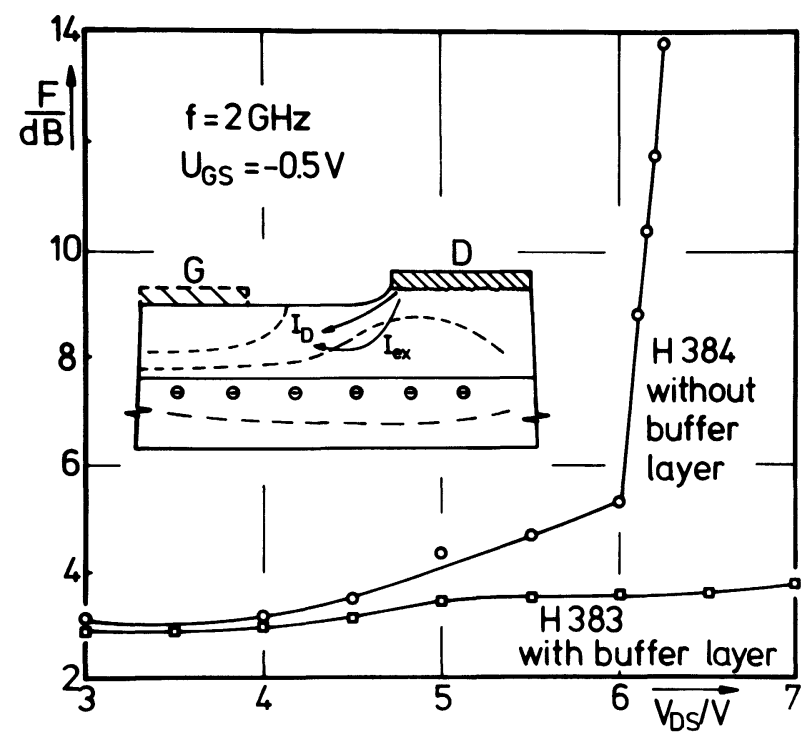

FIG. 3. - Noise figure of GaAs MESFETS and schematic pinch off mechanism by back side gating at the drain contact edge; $\ominus$ captured electrons by interface traps.

in this critical region and shifts the drain breakdown voltage to higher values, a common effect reported in $[6,8]$.

\subsection{INFLUENCE OF THE RECESSED GATE AREA AND THE} EPILAYER THICKNESS. - Recessing the channel selectively in the gate area by chemical etching, before gate evaporation, improves the pinch off [14], noise, high frequency and breakdown [5] properties of buffered and unbuffered devices. GaAs MESFETs fabricated by this process on buffered wafer $\mathrm{H} 573$ (Fig. 1c) have pinch off voltages of $1.3 \mathrm{~V}$ at saturation currents of $30 \mathrm{~mA}$, corresponding to an overall transconductance of $150 \mathrm{mS} / \mathrm{mm}$ [14]. The superior behaviour of these devices comes from the very thin $(\lesssim 0.1 \mu \mathrm{m})$ residual channel below the gate and, keeping the epilayer thickness high between source and gate, by reduction of the source leading resistance. 4Gate MESFETs (gate width $800 \mu \mathrm{m}$, saturation current 50-200 mA) made on the unbuffered wafer D 353, show $f_{\max }$ values of over $40 \mathrm{GHz}$ and noise figures of 2.8-3.0 dB at $8 \mathrm{GHz}$, the intrinsic transconductance being $70-100 \mathrm{mS}$. Here the disadvantage of missing the buffer layer is evident compared with run $\mathrm{H} 573$. Devices on wafer D 188-A with comparable geometry but not recessed gate areas (Fig. 1d) have $f_{\max }$ values of the order of $30-35 \mathrm{GHz}$ and noise figure values of 3.2-3.5 dB at $8 \mathrm{GHz}$. DC-operation up to $14 \mathrm{~V}$ drain voltage was possible for MESFETs D 353. To study the mechanism causing the breakdown behaviour improvement by the recessed gate area [5] in unbuffered devices, channels and MESFETs were fabricated on wafer D 394 (Fig. $1 a, b, f$ ). The results of dc and noise measurements are given on figures 4,5 and 6 . In figure 4 the substrate temperature influence on dc characteristics of device D 394-2 is shown. We realize 


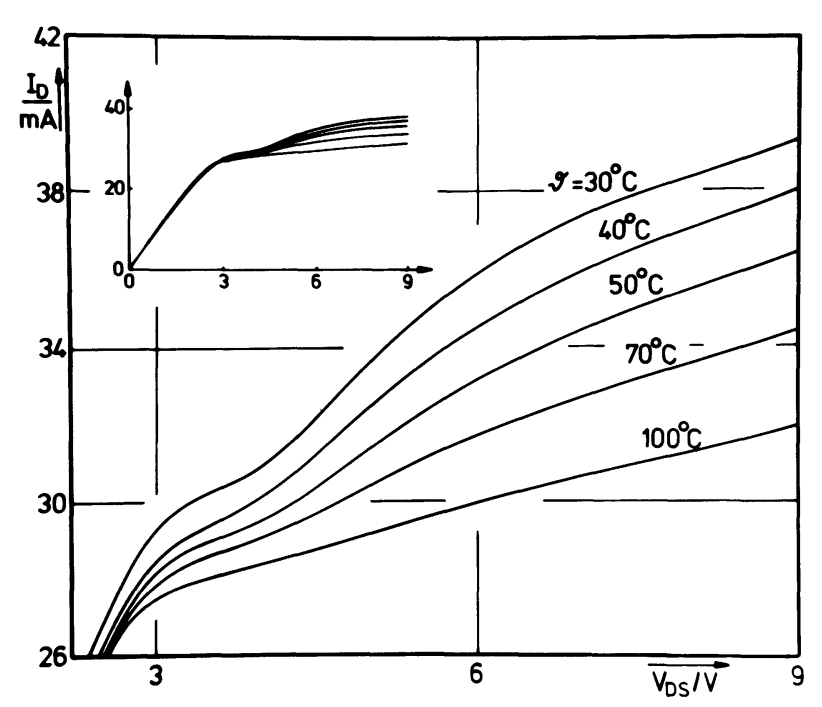

FIG. 4. - Excess current flow in planar epi-channels (Fig. 1a). Device D 394-2. $\vartheta$ : Temperature of the copper heat sink.

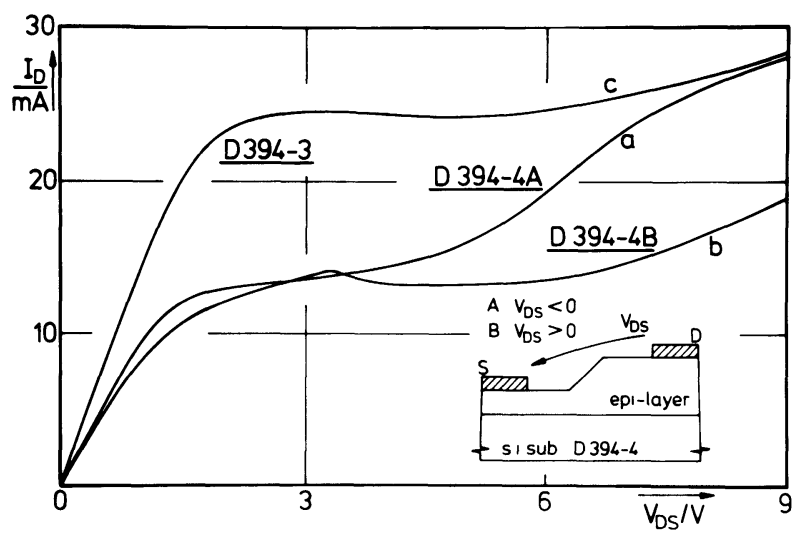

Fig. 5. - Dependence of excess current flow on the thickness of the positive contact. A : S positive biased, B : D positive biased.

an unequivocal additional current flow for $V_{\text {Ds }} \gtrsim 3.7 \mathrm{~V}$. The same current has also been reported in [15] measured on devices H 384 with a channel length of 3.0 and $10 \mu \mathrm{m}$. It seems that the beginning of this excess current flow is nearly independent on the drain to source gap. The negative current temperature gradient on figure 4 indicates an avalanche process originating a substantial part of the additional current, and the saturation tendency for $V_{\text {DS }}>9 \mathrm{~V}$ can be explained by the assumption, that probably only the depleted part of the active layer near the substrate can be carried through by the fast electrons (Fig. 3). DC-measurements on unsymmetrical devices D 394-4 (Fig. 1f) as shown in figure 5, demonstrate clearly, that the critical region, whose breakdown causes the beginning of excess current is the thin positive contact, where the dc-current can be easily pinched off by the back side s.c.l. (curves $a, b$ in figure 5). These characteristics also exclude the assumption of a surface conductivity mechanism being a symmetrical effect.

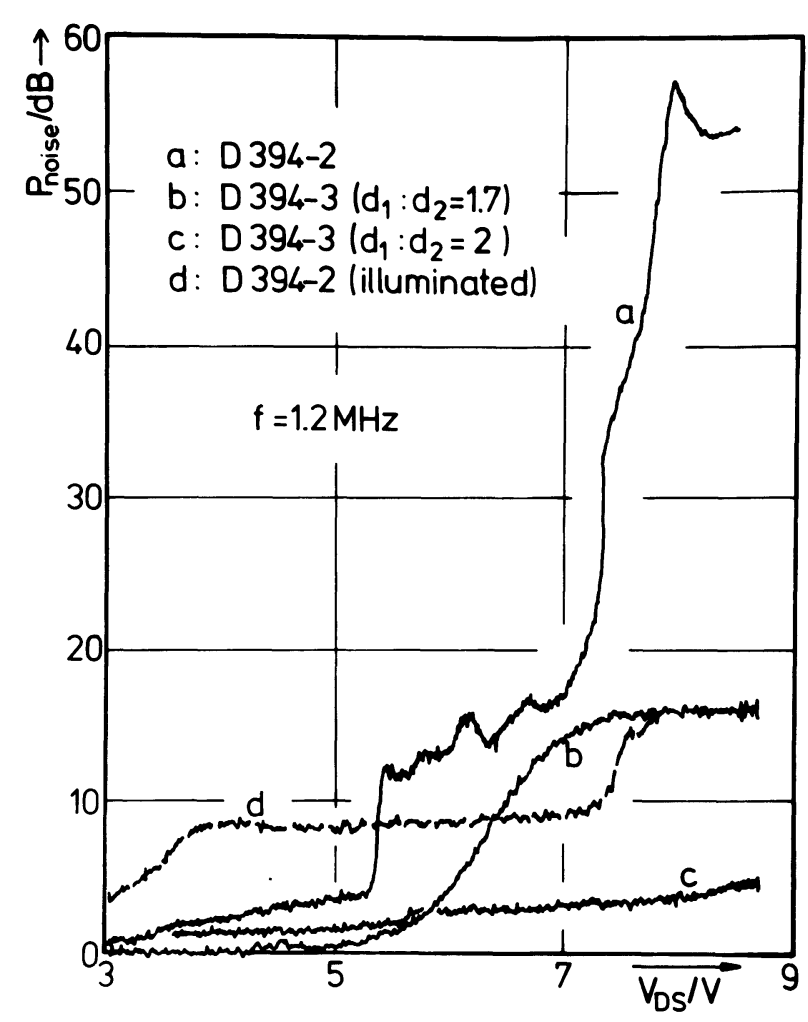

Fig. 6. - Influence of depth of the gate recessed area on low frequency noise of epitaxial GaAs channels. $I_{\text {sat }}$ is reduced by the factor $d_{2} / d_{1}$.

A similar effect on dc-characteristics as due to the buffer layer can be achieved by the gate recessed area (Fig. 5, curve $c$ ). The increase of the dc-current over $I_{\text {sat }}\left(\right.$ defined by $I_{\text {ex }} / I_{\text {sat }}$ ) reaches at $V_{\mathrm{DS}}=9 \mathrm{~V}$ about $15 \%$, whereas in devices D 394-2 (Fig. $1 a$ ) the increment in $I_{\mathrm{D}}$ reaches more than $30 \%$. Measuring $I_{\text {sat }}$ and $I_{\text {ex }}$ of several channels D 394-2 with different thickness $d_{1}$ (Fig. $1 a$ ), we found $I_{\mathrm{ex}}$ to drop with increasing $I_{\text {sat }}\left(\right.$ or $\left.d_{1}\right)$.

So the effect of increasing the drain source breakdown voltage by etching the gate area can be explained from the point of view, that with reducing the effective channel thickness not at the drain end lowers the current density at this critical point. This effect seems to be in principle the same like current reducing by the gate dc-voltage $[5,6,8]$. Figure 6 at least shows that also the steep increase in output noise power of epi-channels of wafer D 394-2 can be reduced or completely suppressed, and shifted to higher voltages by the etched gate area (device D 394-3). Illuminating the device discharges the interface traps and the back side s.c.l. The breakdown is hindered, but low frequency noise dominates especially for lower $V_{\mathrm{DS}}$ values.

4. Summary. - It has been shown, that the insertion of a high purity buffer layer reduces the noise temperature of active layers for FETs by a factor of two and suppresses the breakdown tendency up 
to $9 \mathrm{~V}$, softening the interface between epilayer and substrate, especially at the drain contact. Here, in absence of a buffer layer, the space charge layer of the back side diode can pinch off the channel, causing prebreakdown effects and avalanche noise at drain voltages of 4-6 V and high current densities. Recessing the gate area, a reduction of effective channel thickness and current density at the drain occurs, leading also to a suppression of these effects. On the other hand the reduction of the leading parasitic resistances and the increase of intrinsic transconductance, realized by this method, cause a superior high frequency and noise behaviour of unbuffered MESFETs, whereas buffered devices made by this technique reach $g_{\mathrm{m}}$ values of $150 \mathrm{mS} / \mathrm{mm}$. Most of the discussed effects may be of slighter importance using suitable tested and preselected substrates.

Acknowledgments. - The author wishes to thank Dr. M. Heyen for the fabrication of the active layers, Mrs. G. Neuhauß and Mr. J. Dekkers, D. Leers and M. Bolsen for the fabrication of the test devices. The work has been supported by the SFB 56 Festkörperelektronik.

\section{References}

[1] Nozaki, T. et al., Inst. Phys. Conf. Ser. 24 (1975) 46.

[2] Ogawa, M. et al., IEEE Trans. Microwave Theory Tech. 24 (1976) 300.

[3] Funuta, M. et al., IEEE Trans. Microwave Theory Tech. 24 (1976) 312.

[4] ОнатA, K. et al., IEEE Trans. Electron Devices 24 (1977) 1129.

[3] Hasegawa, F. et al., Proc. IEEE Int. Solid State Circ. Conf. (1978) 118

[6] Үамамото, R. et al., IEEE Trans. Electron Devices 25 (1978) 567.

[7] Tsironis, C., Beneking, H., Proc. 7th Europ. Micr. Conf. (1977) 85.
[8] Tsironis, C., Beneking, H., Proc. Int. Electron Device Meeting (1977) 340 .

[9] Barrera, J., Proc. 5th Conf. on Active Semicond. Devices (Cornell, N. Y.) 1975, 135.

[10] Hewitr, B. et al., Inst. Phys. Conf. Ser. 33 a (1977) 246.

[11] Butlin, R. et al., Inst. Phys. Conf. Ser. 33 a (1977) 237.

[12] Houng, Y., Pearson, G., J. Appl. Phys. 49 (1978) 3348.

[13] Thim, H., Knight, S., Appl. Phys. Lett. 11 (1967) 83.

[14] DekKeRs, J. et al., Electron. Lett. 14 (1978) 272.

[15] Tsironis, C., Beneking, H., Electron. Lett. 13 (1977) 438. 